\title{
RISK OF SPORTS-RELATED MUSCULOSKELETAL INJURIES AMONG ELITE WOMEN BASKETBALL PLAYERS ACCORDING TO POSITION ON THE COURT AND SPORT RESULTS
}

\author{
Saulė Salatkaitė ${ }^{1}$, Toma Garbenytė-Apolinskienė $\dot{1}^{1}$ Laimonas Šiupšinskas ${ }^{1,2}$, \\ Alma Kajèniené ${ }^{1}$, Rimtautas Gudas ${ }^{1}$ \\ Lithuanian University of Health Sciences ${ }^{1}$, Institute of Sports, Kaunas, Lithuania \\ Lithuanian Sports University', Kaunas, Lithuania
}

\begin{abstract}
Background. Basketball is a popular sport around the world, the number of players is growing, the probability to experience trauma is increasing, too. Studies have shown that women sustain $60 \%$ more injuries than men do. Preseason physical examination helps to establish sports specific changes in the body of the athlete and to determine risk factors for training, competition, which cause injury to the players. Research aim was to analyse risk of non-contact musculoskeletal injuries in elite women basketball players according to the position on the court.

Methods. The study involved 100 players in Lithuanian women basketball league who completed the questionnaire about the level of physical fatigue, performed Lower Quarter Y Balance Test ${ }^{\mathbf{T M}}$ and Functional Movement Screen TM tests during pre-season physical examination in 2014. Data were analysed and compared according to player's position on the court (guards and forwards).

Results. The level of physical fatigue during pre-season period was low in both groups. Dynamic stability of the right leg was better in guards (composite score - 105.2 to 101.8 in forwards) while dynamic stability of the left leg remained the same in both groups. Guards had higher total scores in Functional Movement Screen ${ }^{\text {TM }}$ tests pointing to the better quality of basic functional movement patterns.

Conclusions. The guard's playing efficiency during the season was higher than that of forwards and it was associated with better dynamic stability and higher level of physical fatigue at pre-season. Indirect indicators of non-contact musculoskeletal sport injuries showed that guards should have lower risk of non-contact sport-related injuries in women basketball.
\end{abstract}

Keywords: risk of sports trauma, female basketball players, functional movements, dynamic stability.

\section{INTRODUCTION}

$\mathrm{R}$ egular team sports participation has welldocumented health benefits by improving physical fitness, socialization, and other health-related behaviours. However, as with any sport, basketball participation carries the risk of injury (Borowski, Yard, Fields, \& Comstock, 2008; Van der Worp et al., 2011).

The activity patterns of many sports are intermittent in nature, fluctuating randomly from brief periods of maximal or near maximal work to longer periods of moderate- and low-intensity activity (Glaister, 2005). Independently from technical training/skills, training in ball sports (e.g. soccer and basketball) involves dynamic (both aerobic and anaerobic) and static exercises (Akova, Yesilbursa, Sekir, Gur, \& Sedar, 2005). Within this endurance context, numerous explosive bursts of activity are required, including jumping, kicking, tackling, turning, sprinting, changing pace, and sustaining forceful contractions to maintain balance and 
control of the ball against defensive pressure (Stolen, Chamari, Castagna, \& Wisloff, 2005). The findings of the study indicated that physical performance of professional basketball players differs among guards, forwards and centres (Köklü, Alemdaroğlu, Koçak, Erol, \& Fındıkoğlu, 2011), but there is a lack of information to enable the determination of associations between sports injuries and position on the court (Vanderlei et al., 2013).

Basketball is becoming an increasingly popular sport around the world. Increasing numbers of basketball players create a probability of injury growth (Cantwell, 2004; McKay, Goldie, Payne, \& Oakes, 2001). Previous work on middle school athletes has found that the most common body part injured was the knee $(67.9 \%)$, followed by the ankle (21.4\%) and the hand (3.6\%). Of the 57 knee injuries, 35 (61.4\%) occurred during games and 22 (38.6\%) during practice (Barber Foss, Myer, $\&$ Hewett, 2014). Previous research in the highschool setting has shown that in basketball, injuries most often occur to the extremities (hands, wrists, ankles, and knees), with ankle sprain being the most common type of injury and injury location (Messina, Farney, \& DeLee, 1999). Most sports activities always involve a certain level of risk, even when reasonable precautions are implemented. It is essential, therefore, for governing bodies to demonstrate that they have identified the potential risks within their sports and implemented adequate measures to control them.

Also one of the predictors of injury risk is fatigue. Neuromuscular fatigue, defined as an exercise-induced reduction in the maximal voluntary force produced by a muscle or group of muscles is proposed to increase the risk of ACL injury via altered lower limb joint kinematics associated with poor muscle activation patterns (Mclean et al., 2007). Results of one study have shown that neuromuscular fatigue causes a number of biomechanical alterations that may increase the risk of noncontact ACL injury during landing. Also, the fatigue condition combined with a decisionmaking task may represent a worst-case scenario for ACL injury risk and is an area that clearly warrants further research (Borotikar, Newcomer, Koppes, \& McLean, 2008). Therefore, it has been suggested that a fatigue element should be incorporated into injury prevention and rehabilitation programs (Kernozek, Torry, \& Iwasaki, 2008).

The purpose of assessments can vary, but often involve selection, goal setting, program evaluation, and monitoring training progress (Hoffman, Ratamess, Klatt, Faigenbaum, \& Kang, 2007). In addition, assessments can also be used to predict an individual's risk for injury. However, a lot off assessments tend to focus on individual joints or muscle groups that are not consistent with functional movements seen during sport (Mottram \& Comerford, 2008). Although injury prevention remains an important goal, at present little agreement exists regarding the assessment tool that can successfully predict injuries associated with physical training (Kodesh et al., 2015).

A relatively new approach has begun to focus on examining movement patterns as opposed to isolated muscle groups or joints. As a result, a tool to assess characteristics of an individual's functional movement has been developed (Cook, Burton, \& Hoogenboom, 2006). The Functional Movement Screen $^{\mathrm{TM}}\left(\mathrm{FMS}^{\mathrm{TM}}\right)$ is a screening instrument which evaluates selective fundamental movement patterns to determine potential injury risk (Schneiders, Davidsson, Hörman, \& Sullivan, 2011). While some screening methods require advanced training, certification or a period of familiarization, the $\mathrm{FMS}^{\mathrm{TM}}$ is a reliable screening method even when administered by novice examiners (Garrison, Westrick, Johnson, \& Benenson, 2015). The Y Balance Test is a functional screening tool that is used to assess dynamic stability, monitor rehabilitation progress, assess deficits following an injury, and identify athletes at high risk for lower extremity injury (Filipa, Byrnes, Paterno, Myer, \& Hewett, 2010). Although balance has been proposed as a risk factor for sports-related injury, few researchers have used a dynamic balance test to examine this relationship (Plisky, Rauh, Kaminski, \& Underwood, 2006). FMS and dynamic balance test scores may be able to accurately categorize risk of lower extremity injury (Lehr et al., 2013). So our hypothesis was that basketball players' position on the court is associated with the risk of non-contact sports injury.

It is very important to understand that the players are in a risk group (Van der Worp et al., 2011). Exploring the effects of specific rule changes on injury rates can help us identify risk factors in games that may predispose players to injury (Agel et al., 2007). The purpose of our study was to analyse results of pre-season physical examination, risk of non-contact injury and to compare with sports results in elite Lithuanian women basketball players. 


\section{METHODS}

The research was accomplished in Lithuanian University of Health Sciences, Institute of Sports. We got a license from Kaunas Regional Biomedical Research Ethics Committee (No. BEC-KN (B)-90).

Research Participants. Research participants were evaluated in pre-season training period in September of 2014. The study involved Lithuanian women basketball league (LWBL) players. All tests were carried out on the same day for each team. Research included 100 women aged $22.62 \pm$ 5.21 years, average height was $180.40 \pm 8.28 \mathrm{~cm}$, weight $-74.44 \pm 9.42 \mathrm{~kg}$, average body mass index was $21.90 \pm 2.02 \mathrm{~kg} / \mathrm{m}^{2}$. Descriptive variables and demographic data are presented in Table 1.

All respondents participated in the survey voluntarily; they were informed about the purpose of the study. Physical examination consisted of the $\mathrm{Y}$ Balance Test ${ }^{\mathrm{TM}}$ and the Functional Movement Screen ${ }^{\mathrm{TM}}$ tests. The questionnaire about the level of physical fatigue was completed in a free time from tests.

Physical examination and functional movement patterns assessment. The Lower Quarter $\mathrm{Y}$ Balance Test $^{\mathrm{TM}}$ (modified Star
Excursion Balance Test) was used to assess player's dynamic balance. It involves a stance platform to which three pieces of PVC pipes are attached in the anterior, posteromedial and posterolateral reach directions (Figure 1) (Borowski et al., 2008, Butler, Queen, Beckman, Kiesel, \& Plisky, 2013). Plisky, Gorman, Butler, Kiesel, and Underwood (2009) observed that players whose composite reach distance is lower than 96 on the Y Balance Test are at the elevated risk for lower extremity injury. In addition, poor performance in this test is a strong predictor of ankle sprains or helps to find individuals with chronic ankle instability, weak hip abduction and other lower extremity problems (Plisky et al., 2009). The subject stood with the right foot on the centre of the footplate and the most distal aspect of the subject's barefoot was at the starting line. Three trials were completed in each direction (anterior, posteromedial, posterolateral). The same process was repeated using the contralateral limb as the stance limb. A trial was discarded if the subject failed to maintain unilateral stance (Borowski et al., 2008), touched down on the reaching foot (Butler et al., 2013), or failed to return to the starting position (Cantwell, 2004). Performance for all trials was recorded, and

\begin{tabular}{|c|c|c|c|c|}
\hline Group & Age (years) & Height $(\mathbf{c m})$ & Weight $(\mathbf{k g})$ & BMI $\left(\mathbf{k g} / \mathbf{m}^{2}\right)$ \\
\hline Guards $(n=38)$ & $22.65 \pm 5.77$ & $174.01 \pm 4.39^{\wedge}$ & $65.34 \pm 7.48^{\diamond}$ & $21.54 \pm 1.92$ \\
\hline Forwards $(n=62)$ & $23.11 \pm 5.43$ & $184.26 \pm 5.98^{\wedge}$ & $74.15 \pm 8.35^{\diamond}$ & $21.82 \pm 2.14$ \\
\hline
\end{tabular}

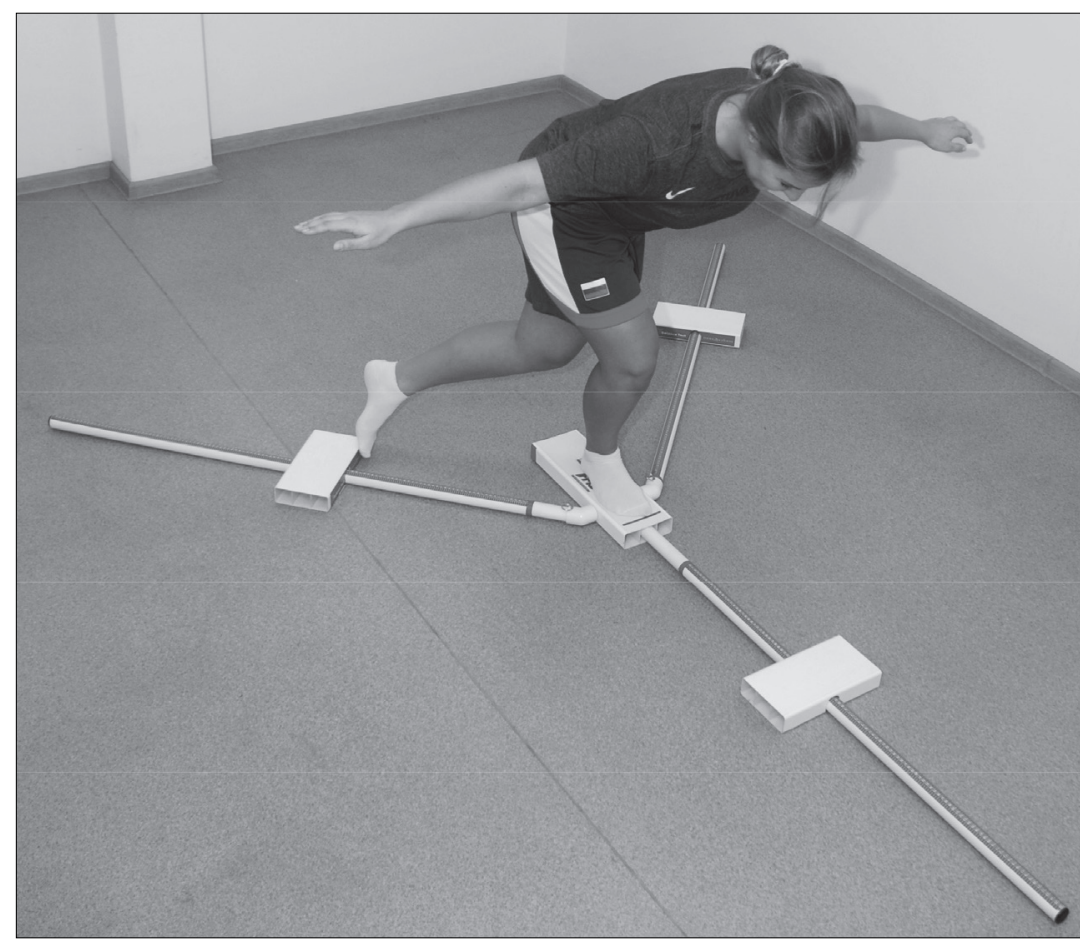

Table 1. Summary of demographic data for guards and forwards

Notes. * $-p<.05$ compared between groups; $\wedge, \diamond p<.001$.

Figure 1. Posterolateral reach using the $\mathbf{Y}$ Balance Test $\mathrm{Kit}^{\mathrm{TM}}$ 
the maximum reach score for each reach direction was extracted for data analysis. The composite score on the test was calculated by averaging the maximum scores for each reach direction after the maximum scores were normalized to limb length (Butler et al., 2013).

The Functional Movement Screen $^{\mathrm{TM}}$ was developed by Cook et al. (2006). The Functional Movement Screen ${ }^{\mathrm{TM}}\left(\mathrm{FMS}^{\mathrm{TM}}\right)$ is one of the new generation screening assessments evaluating selective fundamental movement patterns to determine potential injury risk (Cook et al., 2006). The FMS ${ }^{\mathrm{TM}}$ includes seven tests that are scored on a zero - three ordinal scale. The seven tests are the deep squat, hurdle step, lunge, shoulder mobility, active straight leg raise, push-up, and rotary stability (Figure 2). A score of three indicates that the movement was completed as instructed and is free of movement compensation and pain. A score of two indicates that the subject could complete the movement pain-free but with some level of compensation; a score of one indicates that the subject could not complete the movement as instructed; a zero is assigned if the subject experiences pain with any portion of the movement. Five of the seven tests that comprise the FMS are performed and scored separately for the right and left sides of the body. When assigning a score to a test that incorporates both left and right sides, the lesser of the two scores is used for a final event score. Overall FMS scores can range from zero to 21. Final FMS score was obtained when the results of FMS tests were summed (O'Connor, Deuster, Davis, Pappas, \& Knapik, 2011).

Measurement of level of physical fatigue and sports results. The players completed Physical Fatigue Assessment section from the Pre-participation Health Questionnaire (European Athletics Championships, Göteborg 2013). Each athlete had to mark a point on $10 \mathrm{~cm}$ line, which the best described her physical fatigue level in pre-season trainings. This point was measured with a ruler and presented as a numeric value. The player's efficiency was calculated by efficiency score of all games per season. The players were grouped by positions in guards and forwards. Results were compared between groups and with the efficiency score and the level of fatigue.

Statistical analysis. The analysis was performed using SPSS for Windows software (version 22.0). The study data was processed determining the arithmetic means of the research group (x), the dispersion was evaluated in association with standard deviations (S). To compare differences between groups, Independent Samples test was used for independent samples, which was normally distributed. The level of significance was set at $p<.05$. Correlation coefficients of tests results and efficiency were analysed using Spearman's correlation coefficient.

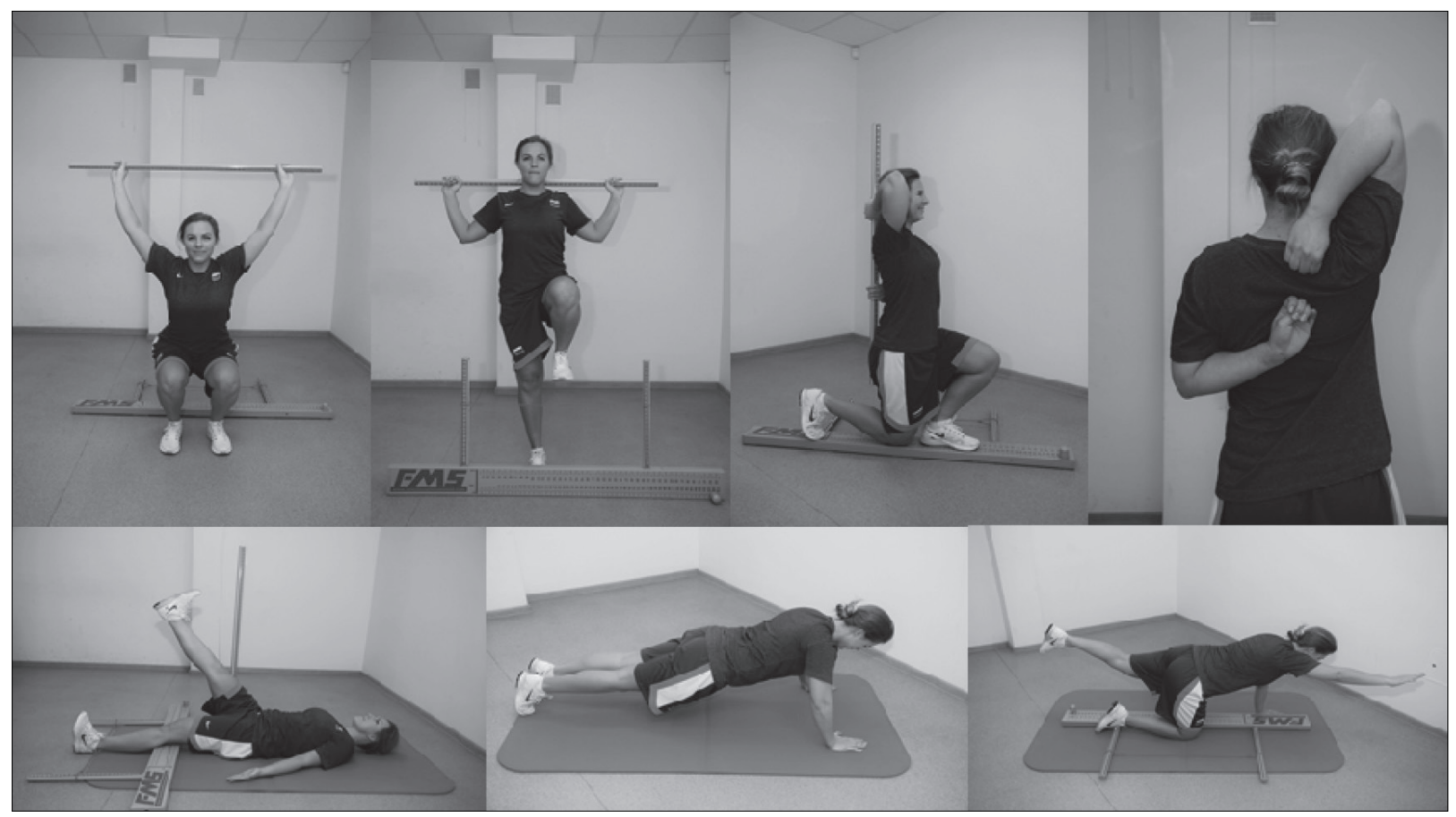

Figure 2. Functional Movement Screen $\left(\right.$ FMS $\left.^{\mathrm{TM}}\right)$ tests: deep squat, hurdle step, in-line lunge, shoulder mobility, active straight leg rise, push-up and rotary stability 


\section{RESULTS}

Results of physical examination and functional movement patterns. The averages of total FMS score of groups are given in Figure 3. The result of guards was $16.47 \pm 1.94$ points out of 21. The average of total FMS score $15.79 \pm 1.69$ was in forwards group. The total FMS score was statistically significant higher in guards $(p=.041)$.

Composite score of left leg obtained from the $\mathrm{Y}$ Balance Test in guards group was $105.21 \pm 7.32$, in forwards group $-102.69 \pm 5.59$ score. Composite score of right leg obtained from the Y Balance Test in guards group was $105.10 \pm 7.54$, in forwards group $-101.83 \pm 5.69$ score. The dynamic balance of right leg was statistically significantly better $(p=.025)$ in guards (Figure 4).
Evaluation of efficiency of players and physical fatigue during pre-season period. Efficiency score in guards group was $3.55 \pm 0.59$, in forward group $-5.91 \pm 0.75$. There were statistically significantly different $(p=.029)$ results between groups. Evaluation of physical fatigue during preseason period had shown that the score of fatigue in guards group was $3.64 \pm 2.15$ points out of 10 . Fatigue score in forwards group was $4.26 \pm 2.05$ points. There were no statistically significant differences between groups (Table 2).

Table 2. Efficiency of groups and physical fatigue intensity in the last month in 2013/2014 pre-season period

\begin{tabular}{|c|c|c|}
\hline Group & Fatigue (cm) & Efficiency \\
\hline Guards & $3.64 \pm 2.15$ & $3.55 \pm 0.59^{*}$ \\
\hline Forwards & $4.27 \pm 2.05$ & $5.91 \pm 0.75^{*}$ \\
\hline
\end{tabular}

Note. $* p<.05$
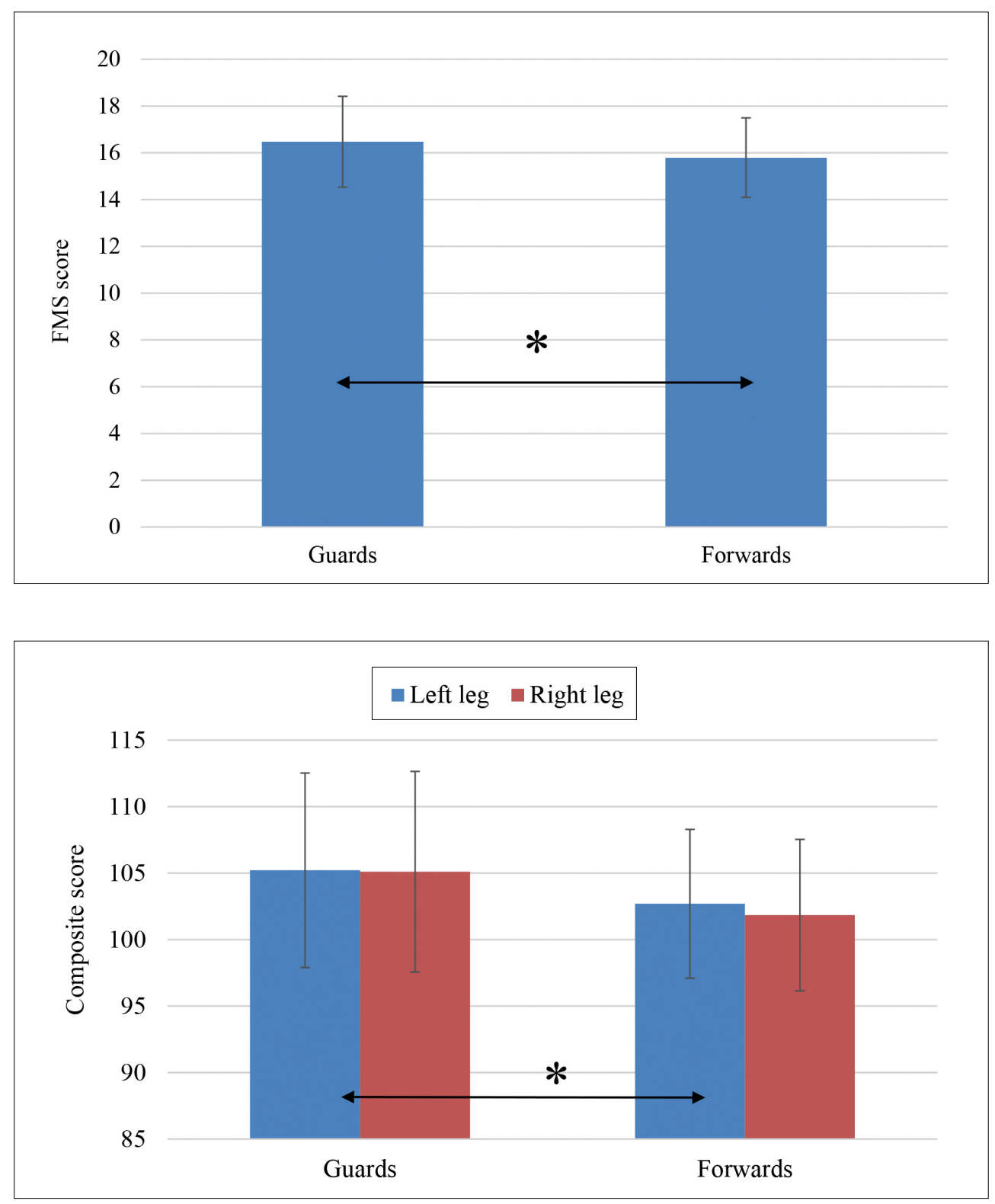

Figure 3. The final Functional Movement Screen $\left(\right.$ FMS $\left.^{\mathrm{TM}}\right)$ score of the groups

Note. * $p<.05$

Figure 4. Left and right legs' composite scores of $Y$ Balance Test ${ }^{\mathrm{TM}}$ of the groups

Note. $* p<.05$. 
Statistically significant moderate positive correlations were found between players' efficiency, fatigue and dynamic balance in guards. Better dynamic stability of lower limbs in guards is associated with higher players' efficiency and with higher level of physical fatigue (Table 3).

Table 3. Correlation coefficients of efficiency, fatigue, intensity and Y Balance composite scores in guards and forwards

\begin{tabular}{|c|c|c|c|c|}
\hline \multirow{2}{*}{ Variables } & \multicolumn{2}{|c|}{ Guards } & \multicolumn{2}{c|}{ Forwards } \\
\cline { 2 - 5 } & Efficiency & Fatigue & Efficiency & Fatigue \\
\hline $\begin{array}{c}\text { Y Balance test } \\
\text { Composite } \\
\text { score } \\
\text { Left leg }\end{array}$ & $.448^{*}$ & $.365^{*}$ & .037 & -.184 \\
\hline $\begin{array}{c}\text { Y Balance test } \\
\text { Composite } \\
\text { score } \\
\text { Right leg }\end{array}$ & $.414^{*}$ & $.350^{*}$ & .013 & -.068 \\
\hline
\end{tabular}

Note. $* p<.05$.

In the group of forwards, significant weak positive correlation was found between players' efficiency and fatigue indicating that higher forwards' efficiency might be associated with elevated level of physical fatigue (Table 4).

Table 4. Correlation coefficients of efficiency and fatigue intensity in guards and forwards

\begin{tabular}{|l|c|c|}
\hline \multirow{2}{*}{ Variable } & \multicolumn{2}{|c|}{ Efficiency } \\
\cline { 2 - 3 } & Guards & Forwards \\
\hline Fatigue & .280 & $.295^{*}$ \\
\hline
\end{tabular}

Note. ${ }^{*} p<.05$.

\section{DISCUSSION}

The main aim of this study was to analyse results of pre-season physical examination: assess the level of non-contact injury risk using functional tests, set the level of physical fatigue and analyse the efficiency of sports results in elite Lithuanian women basketball players according to the players' position on the court.

Our data revealed that guards and forwards in our study had no increased risk level of injury according the total FMS score in pre-season period - the scores where higher than the injury risk cut-off point found in literature - score of $\leq 14$. In the study of O'Connor et al. (2011), FMS scores $\leq 14$ were associated with increased injury risk, although the sensitivity was low. In the study of Schneider, Davidsson, Hörman, and Sullivan (2011), among young active population, 31\% of the participants had a score of 14 or less, but the average of total FMS score in females was similar to that in our findings $-15.6 \pm 0.2$. Other research showed that basketball players had the worst results of FMS test compared to football and handball players (Letafatkar, Hadadnezhad, Shojaedin, \& Mogamadi, 2014). Some authors claim that if the FMS result is 14 or less, it can be said that the athlete has 11 times increased risk of sports injury compared with players who have scored more than 14 points (Kiesel, Plisky, \& Voight, 2007).

The results of Y Balance Test of guards and forwards showed that composite scores in both groups were higher than the cut-off point of injury risk level $(\leq 94)$ (Plisky et al., 2006). In our study guards had statistically significantly better dynamic balance than forwards on the right limb. Gribble, Kelly, Refshauge, ad Hiller (2013) showed good interrater reliability of the test: whether the chosen outcome was average or maximum scored and used raw or normalized data, the anterior, posteromedial, and posterolateral directions had excellent reliability. In Butler's study, college football players who scored below 89.6 were 3.5 times more likely to get injured (Butler et al., 2013). Some authors claim that players with poor dynamic balance are more likely to experience ankle injury (McGuine, Greene, Best, \& Leverson, 2000). Interestingly, Plisky et al. (2006) found that female basketball players with composite score less than 94 were more than 6 times more likely to have a lower extremity injury, but this risk factor was not significant for boys.

Results of the questionnaire about physical fatigue (European Athletics Championships, Göteborg 2013) showed that there were no statistically significantly differences between fatigue in groups. However, some authors say that neuromuscular fatigue is proposed to increase the risk of ACL injury via altered lower limb joint kinematics associated with poor muscle activation patterns (McLean et al., 2007). For example, neuromuscular fatigue has been demonstrated to induce changes in knee flexion, knee abduction and hip internal rotation in female NCAA athletes performing single-leg landings (McLean \& Samorezov, 2009).

Players were classified and analysed according to the position on the court - guards and forwards. Results showed that guard's higher playing efficiency score and higher physical fatigue level during pre-season training was associated with better dynamic balance of right limb. Increased efficiency score in forwards was associated with 
higher level of physical fatigue in pre-season training period. We decided to split players in two positions because basketball player's body height and body mass is one of the factors that determine court position; guards are significantly shorter than forwards (Köklü et al., 2011). Vanderlei et al. (2013) found that individual (age, height and weight) and training (length of time in training and number of practice hours per week) characteristics might be associated with intrinsic and extrinsic risk factors for guards and forwards, and body mass might be a risk factor for all positions. Findings of another study demonstrate that guards have higher $\mathrm{VO}_{2}$ max values than forwards (Köklü et al., 2011). This can explain obtained correlations in forward group of our investigation.

\section{CONCLUSION}

The level of physical fatigue during preseason training period of elite Lithuanian women basketball players was low and it was the same in guards and forwards. Dynamic stability of right leg and fundamental functional movements were better in guards than in forwards. The guards' playing efficiency during the season was higher than that of forwards and it was associated with better dynamic stability and higher level of physical fatigue at pre-season. Indirect indicators of noncontact musculoskeletal sports injuries showed that guards should have lower risk of non-contact sports-related injuries in women basketball.

A major strength of this study was the large number and comprehensive descriptive profile of the participants, which allowed both meaningful comparisons between groups and the potential to make useful future comparisons with similar studies. Registration and analysis of sports injuries during the season might get us more accurate results about the prediction of sports traumas. Future studies should focus on interventions that lower the risk of non-contact sports related injuries.

\section{REFERENCES}

Agel, J., Olson, D. E., Dick, R., Arendt, E. A., Marshall, S. W., \& Sikka, R. S. (2007). Descriptive epidemiology of collegiate women's basketball injuries: National Collegiate Athletic Association injury surveillance system, 1988-1989 through 2003- 2004. Journal of Athletic Training, 42, 202-210. PMCID: PMC1941290

Akova, B., Yesilbursa, D., Sekir, U., Gur, H., \& Sedar, A. (2005). Myocardial performance and aortic elastic properties in elite basketball and soccer players: Relationship with aerobic and anaerobic capacity. Journal of sports Science and Medicine, 4, 185-194. PMCID: PMC3880886

Barber Foss, K. D., Myer, G. D., \& Hewett, T. E. (2014). Epidemiology of basketball, soccer, and volleyball injuries in middle-school female athletes. Physician and Sports Medicine, 42(2), 146-153. doi: 10.3810/ psm.2014.05.2066

Borotikar, B. S., Newcomer, R., Koppes, R., \& McLean, S. G. (2008). Combined effects of fatigue and decision making on female lower limb landing postures: Central and peripheral contributions to ACL injury risk. Clinical Biomechanics, 23, 81-92. doi: http://dx.doi. org/10.1016/j.clinbiomech.2007.08.008

Borowski, L. A., Yard, E. E., Fields, S. K., \& Comstock, R. D. (2008). The epidemiology of US high school basketball injuries, 2005-2007. The American Journal of Sports Medicine, 36(12), 2328-2335. doi: $10.1177 / 0363546508322893$

Butler, R. J., Lehr, M. E., Fink, M. L., Kiesel, K. B., \& Plisky, P. J. (2013). Dynamic balance performance and noncontact lower extremity injury in college football players: An initial study. Sports Health, 5(5), 417-422. doi: $10.1177 / 1941738113498703$

Butler, R. J., Queen, R. M., Beckman, B., Kiesel, K. B., \& Plisky, P. J. (2013). Comparison of balance in adolescent male soccer players from Rwanda and the United States. The International Journal of Sports Physical Therapy, 8(6), 749-755. PMCID: PMC3867068

Cantwell, J. D. (2004). The physician who invented basketball. American Journal Cardiology, 93, 1075-1077. doi: http://dx.doi.org/10.1016/j.amjcard.2003.12.068

Cook, G., Burton, L., \& Hoogenboom, B. (2006). Pre-participation screening: The use of fundamental movements as an assessment of function - Part 1. North American Journal of Sports Physical Therapy, 1(2), 6272. PMCID: PMC2953313

Filipa, A., Byrnes, R., Paterno, M. V., Myer, G. D., \& Hewett, T. E. (2010). Neuromuscular training improves performance on the star excursion balance test in young female athletes. Journal of Orthopaedic \& Sports Physical Therapy, 40(9), 551-558. doi: 10.2519/ jospt.2010.3325

Garrison, M., Westrick, R., Johnson, M. R., \& Benenson, J. (2015). Association between the functional movement screen and injury development in college athletes. The International Journal of Sports Physical Therapy, 10(1), 21-28. PMCID: PMC4325284.

Glaister, M. (2005). Physiological responses, mechanisms of fatigue and the influence of aerobic fitness. Sports Medicine, 35(9), 757-777. PMCID: PMC16138786

Gribble, P. A., Kelly, S. E., Refshauge, K. M., \& Hiller, C. E. (2013). Interrater reliability of the star 
excursion balance test. Journal of Athletic Training, 48(5), 621-626. doi: 10.4085/1062-6050-48.3.03

Hoffman, J. R., Ratamess, N. A., Klatt, M., Faigenbaum, A. D., \& Kang, J. (2007) Do bilateral power deficits influence direction specific movement patterns? Research in Sports Medicine, 15(2), 125-132. doi: 10.1080/15438620701405313

Kernozek, T. W., Torry, M. R., \& Iwasaki, M. (2008). Gender differences in lower extremity landing mechanics caused by neuromuscular fatigue. American Journal of Sports Medicine, 36, 554-565. doi: http:// dx.doi.org/10.1177/0363546507308934

Kiesel, K., Plisky, P. J., \& Voight, M. L. (2007). Can serious injury in professional football be predicted by a preseason functional movement screen? North American Journal of Sports Physical Therapy, 2(3), 147-158. PMCID: PMC2953296

Kodesh, E., Shargal, E., Kislev-Cohen, R., Funk, S., Dorfman, L., Gil Samuelly, G., ... Sharvit, N. (2015). Examination of the effectiveness of predictors for musculoskeletal injuries in female soldiers. Journal of Sports Science and Medicine, 14, 515-521. PMCID: PMC4541114.

Köklü, Y., Alemdaroğlu, U., Koçak, F. Ü., Erol, A. E., \& Findıkoğlu, G. (2011). Comparison of chosen physical fitness characteristics of Turkish professional basketball players by division and playing position. Journal of Human Kinetics, 30, 99-106. doi: 10.2478/v10078-0110077-y

Lehr, M. E., Plisky, P. J., Butler, R. J., Fink, M. L., Kiesel, K. B., \& Underwood, F. B. (2013). Fieldexpedient screening and injury risk algorithm categories as predictors of noncontact lower extremity injury. Scandinavian Journal of Medicine \& Science in Sports, 23(4), 225-232. doi: 10.1111/sms. 12062

Letafatkar, A., Hadadnezhad, M., Shojaedin, S., \& Mogamadi, E. (2014). Relationship between functional movement screening score and history of injury. The International Journal of Sports Physical Therapy, 9(1), 21-27. PMCID: PMC24567852

McGuine, T. A., Greene, J. J., Best, T., \& Leverson, G. (2000). Balance as a predictor of ankle injuries in high school basketball players. Clinical Journal of Sport Medicine, 10, 239-244. PMCID: PMC11086748

McKay, G. D., Goldie, P. A., Payne, W. R, \& Oakes, B. W. (2001). Ankle injuries in basketball: Injury rate and risk factors. British Journal of Sports Medicine, 35, 103108. doi:10.1136/bjsm.35.2.103

McLean, S. G., \& Samorezov, J. E. (2009). Fatigueinduced ACL injury risk stems from degradation in central control. Medicine \& Science in Sports \& Exercise, 41, 1661-1672. doi: 10.1249/MSS.0b013e31819ca07b

McLean, S. G., Fellin, R. E., Suedekum, N., Calabrese, G., Passerallo, A., \& Joy, S. (2007). Impact of fatigue on gender-based high-risk landing strategies. Medicine \& Science in Sports \& Exercise, 39, 502-14. doi: 10.1249/mss.0b013e3180d47f0

Messina, D. F., Farney, W. C., DeLee, J. C. (1999). The incidence of injury in Texas high school basketball. A prospective study among male and female athletes. American Journal of Sports Medicine, 27(3), 294-299. PMCID: PMC10352762

Mottram, S., \& Comerford, M. (2008). A new perspective on risk assessment. Physical Therapy in Sport, 9(1), 4051. doi: 10.1016/j.ptsp.2007.11.003.

O’Connor, F. G., Deuster, A., Davis, J., Pappas, C. G., \& Knapik, J. (2011). Functional movement screening: Predicting injuries in officer candidates. Medicine \& Science In Sports \& Exercise, 43(12), 2224-2230. doi: 0195-9131/11/4312-2224/0

Plisky, P. J., Gorman, P. P., Butler, R. J., Kiesel, K. B., \& Underwood, F. B. (2009). The reliability of an instrumented device for measuring components of the star excursion balance test. North American Journal of Sports Physical Therapy, 4(2), 92-99. PMCID: PMC2953327

Plisky, P. J., Rauh, M. J., Kaminski, T. W., \& Underwood, F. B. (2006). Star excursion balance test as a predictor of lower extremity injury in high school basketball players. Journal of Orthopedic \& Sports Physical Therapy, 36(12), 911-919. doi:10.2519/ jospt.2006.2244

Schneiders, A. G., Davidsson, A., Hörman, E., \& Sullivan, S. J. (2011). Functional movement screen normative values in a young, active population. The International Journal of Sports Physical Therapy, 6(2), 75-82. PMCID: PMC3109893

Stolen, T., Chamari, K., Castagna, C., \& Wisloff, U. (2005). Physiology of soccer: An update. Sports Medicine, 35(6), 501-36. doi: 0112-1642/05/0006-0501/\$34.95/0

Vanderlei, F. M., Bastos, F. N., Lemes, I. R., Vanderlei, L. C. M., Netto, J. J., \& Pastre, C. M. (2013). Sports injuries among adolescent basketball players according to position on the court. International Archives of Medicine, 6(5), 2-4. doi: 10.1186/1755-7682-6-5

Van der Worp, H., Van Ark, M., Roerink, S., Pepping, G. J., Van den Akker-Scheek, I. \& Zwerver, J. (2011). Risk factors for patellar tendinopathy: A systematic review of the literature. British Journal of Sports Medicine, 45(5), 446-452. doi: 10.1136/ bjsm.2011.084079 